RESEARCH ARTICLE

\title{
Preservation is Political: Enacting Contributive Justice and Decolonizing Transnational Archival Collaborations
}

\author{
T-Kay Sangwand \\ UCLA Library, US \\ tksangwand@ucla.edu
}

\begin{abstract}
This article contributes to critical archival studies discourse and builds upon the theoretical and practical work accomplished under the postcustodial rubric in order to propose an archival framework that is explicitly oriented in the service of justice. Global north/south postcustodial collaborations highlight the ethical and practical obligation of adopting an archival framework that accounts for expanded notions of stewardship and narrative agency. As an archivist based in US academic libraries who works primarily on transnational archival collaborations in the global south, I want to introduce the concept of contributive justice to these postcustodial transnational collaborations because it reframes the role of the partner organization in the global south and acknowledges the agency of all partners (Gomberg 2007). By drawing upon my experiences facilitating transnational archival partnerships between US academic libraries and institutions in Cuba, El Salvador, and Rwanda, I build upon Michelle Caswell's (2017) suggested actions for dismantling white supremacy within US archives by offering concrete ways archivists can utilize a contributive justice framework to decolonize archival practices (i.e., appraisal, description, access) within transnational partnerships. By offering these examples, we can begin to both imagine and enact a more just and liberatory archival praxis. As Caswell states, 'through the lens of liberatory archival imaginaries, our work ... does not end with the limits of our collection policies, but rather, it is an ongoing process of conceptualizing what we want the future to look like' (2014a: 51). The stakes are high in the shaping of our collective histories, and we all have the responsibility of envisioning and enacting liberatory archival futures.
\end{abstract}

Keywords: postcustodial archives; social justice; critical archival studies; Cuba; ethics; global south

\section{Introduction}

The work of preserving and presenting the past is inherently political, whether it is in overt acts such as preserving Confederate statues or documenting the stories of genocide survivors, more insidious acts such as privileging elite voices in archives' appraisal policies, or quietly subversive acts such as centering indigenous epistemologies over colonial US references in archival description. ${ }^{1}$ While the archives profession has long espoused itself as a neutral force on the historical record, many scholars and practitioners, from Howard Zinn (1977) to Joan Schwarz and Terry Cook (2002) to Verne Harris (2007) to Anne Gilliland (2011) to Michelle Caswell (2015) to Jarrett Drake (2016) to Tonia Sutherland (2017), have made compelling arguments dispelling the myth of neutrality and challenging the inherent good of the information profession.

As the world witnessed in Charlottesville, Virginia in 2017 with the killing of social justice activist Heather Heyer by James Alex Fields Jr. at a white nationalist rally protesting the removal of a Confederate statue, lives are literally at stake as we negotiate whose narratives shape the historical record and public memory. Heyer's death is a grave reminder of the need to continually and critically re-examine archival frameworks and envision new ones that explicitly reorient our work in service of justice. As archivists, we have agency, and indeed the responsibility, to recognize and address the symbolic violences perpetuated in our archives

\footnotetext{
'This essay is based on the keynote talk of the same name delivered at Library of Congress' National Digital Stewardship Residency Symposium on August 17, 2017, the same week that Heather Heyer was killed by white supremacist James Alex Fields Jr. while protesting a white nationalist rally in Charlottesville, Virginia.
} 
and the inequities perpetuated by our archival practices. I urge us to be unapologetically clear about our ethical stances as archivists because the historical record depends on it.

This article aims to contribute to critical archival studies discourse in two ways: 1) by introducing the concept of contributive justice to postcustodial praxis in order to situate postcustodial praxis within an explicitly social justice framework for 'the ultimate goal of transforming archival practice and society writ large' (Caswell, Punzalan, and Sangwand 2017: 2; Gomberg 2007); and 2) by using the concept of contributive justice to build upon Michelle Caswell's (2017) suggestions for dismantling white supremacy in US archives and expand upon their application in a transnational context in order to decolonize postcustodial collaborations between global north and south institutions. ${ }^{2,3}$ I will apply contributive justice to postcustodial archival praxis and frame Caswell's suggestions in a transnational context by drawing upon my experiences leading transnational postcustodial collaborations in Rwanda and Central America for the Human Rights Documentation Initiative (HRDI) at the University of Texas at Austin (UT Austin) and in Cuba for the International Digital Ephemera Project (IDEP) at the University of California, Los Angeles (UCLA) ${ }^{4}$

\section{Contributive Justice and Decolonizing Global North/South Collaborations}

While most of us are familiar with the concept of distributive justice, or the equitable 'distribution of resources, wealth, power, rewards, and respect among all or select stakeholders in society,' the concept of contributive justice is less familiar (Mehra, Rioux, and Albright 2010: 4822). Distributive justice is 'based on theories of fairness, status, and right' and emphasizes distribution and what stakeholders will get or receive (Mehra, Rioux, and Albright 2010: 4822). While this is an important and necessary framework of justice, it should not be our only lens for understanding justice because the equitable part of distribution can be the most difficult, or impossible, to determine (Gomberg 2016: 31). Our understanding of justice is enriched when we consider the concept of contributive justice, which emphasizes that justice is achieved not when certain benefits are received, but rather when there is both the duty and opportunity for everyone to contribute labor and decision-making (Gomberg 2007; Merlo-Vega and Chu 2015).

The concept of contributive justice first emerged in the information profession literature through discussions of information flows and intellectual property, particularly in Africa, and re-emerged a decade later in a public library context (Lipinski and Britz 2000; Britz and Lipinski 2001; Britz and Lor 2003; Britz 2004; Britz and Lor 2004a; Lor and Britz 2004b; Lor and Britz 2007; Merlo-Vega and Chu 2015). Britz et al. draw upon the United States Catholic Bishops' use of contributive justice:

Social justice implies that persons have an obligation to be active and productive participants in the life of society and that society has a duty to enable them to participate in this way. This form of justice can also be called 'contributive,' for it stresses the duty of all who are able to help create the goods, services, and other nonmaterial or spiritual values necessary for the welfare of the whole community. (1986: 17)

Merlo-Vega and Chu draw upon political philosopher Paul Gomberg's use of contributive justice: 'it is not about the benefits people receive (who gets what, or distribution); rather, justice is achieved by what one gives to others (who gives what, or contribution). There needs to be both duty and opportunity to contribute, because without contributions there isn't anything to distribute' (2015: 303). In other words, contributive justice works in tandem with distributive justice when distribution of resources advances opportunities and responsibilities to contribute.

\footnotetext{
${ }^{2}$ Critical archival studies is defined as approaches that '(1) explain what is unjust with the current state of archival research and practice, (2) posit practical goals for how research and practice can and should change, and/or (3) provide the norms for such critique' (Caswell, Punzalan, and Sangwand, 2017: 2).

${ }^{3}$ The term 'global south' refers to the countries/regions that were previously referred to as 'underdeveloped' or part of the 'developing world' or 'third world.' The term gained wider usage in the late 1990s and early 2000s as discourse on the impacts of globalization heightened and people sought terminology with less negative implications. While recognizing the geographic imprecision of the term 'global south,' I use it as an inclusive term to refer to 'countries and regions formerly colonized by Western Europe' (and I would add the US) that 'retain economic, cultural, and political commonalities that relate to the experience of colonization, as well as a position in today's global power structures that reflects that experience' (Schwarz and Boatca 2015: 17). Or, more succinctly stated, we can understand the global south and north as 'the victims and the benefactors of global capitalism' (Eriksen 2015: 4). The 'global south' countries discussed in this article are Cuba, Guatemala, and Rwanda.

${ }^{4}$ I worked as the Human Rights Archivist at UT Austin from 2009-15 and have been working as Librarian for Digital Collection Development at UCLA since 2016.
} 
Since the contributive justice framework recognizes the agency of all actors and requires a collective responsibility to contribute, it is a fitting framework for postcustodial archival praxis oriented in service of justice. Within the distributive justice model, global south partners are defined by their deficit (i.e., a lack of resources or expertise). In the contributive justice model, global south entities are valued as equal partners for their ability to contribute expertise and labor. Thus, contributive justice and its emphasis on agency and the responsibility of all to contribute is a useful starting point for decolonizing postcustodial archival praxis in global north/south collaborations.

The postcolonial studies field has yielded numerous nuanced definitions and analyses of imperialism, colonialism, and decolonization. For the purposes of this article, I will borrow from indigenous scholar Linda Tuhiwai Smith's work, which explains imperialism and colonialism as interconnected processes that typically entail 'economic expansion,' 'the subjugation of "others,"' and 'a discursive field of knowledge' (the latter a process in which archives play a key role) (1999: 21). Colonialism and imperialism are usually tied to events such as "'discovery," conquest, exploitation, distribution and appropriation' (Tuhiwai Smith 1999: 21). Therefore, a 'decolonizing archival practice' can be characterized as a process that work towards undoing imperialism and colonialism's 'complete disorder to colonized peoples, disconnection from their histories ... their languages ... their own ways of thinking, feeling, and interacting with the world' and must necessarily center these communities in the reclaiming of their humanity and retelling of their own stories as a powerful form of resistance (Tuhiwai Smith 1999: 28, 34-35).

In the wake of the US 2016 elections, archival studies scholar Michelle Caswell published 'Teaching to Dismantle White Supremacy in Archives' (2017), which provided concrete actions that archivists can take to dismantle white supremacy in their archival practices. While Caswell's actions for dismantling white supremacy are geared towards US-based archives and archivists, they also resonate strongly with postcustodial efforts aimed at decolonizing archival practice in global north/south collaborations (Sangwand 2015). The following sections will outline why a social justice-oriented postcustodial praxis is necessary, as well as apply the concept of contributive justice to postcustodial archival praxis to provide concrete examples of how archivists can work towards decolonizing global north/south collaborations.

\section{Postcustodial Theory of Archives, Academic Research Libraries and Global South Collaborations}

As Nicolas Barker (2007) has aptly stated about research libraries, "[they] want to be known for their distinctive collections, not by some characteristic shared by every other library.' In pursuit of this recognition, research libraries are directing more resources to building distinctive collections that will distinguish them from their peers. Historically, academic libraries' distinctive collections were often comprised of physical cultural patrimony purchased or otherwise taken from its country or community of origin. Currently, one of academic libraries' methods for building their distinctive collections is by initiating postcustodial partnerships with institutions, particularly in the global south, who are deemed to hold valuable materials for research and teaching but do not have the resources or expertise to make them available to an audience outside their immediate geographic area. These postcustodial partnerships are centered on the idea that 'archivists will no longer physically acquire and maintain records, but that they will provide management oversight for records that will remain in the custody of the record creators' (SAA 2005a).

Yet, due to histories of imperialism, military and political interventions, and neoliberal economic policies, large US educational institutions have historically received and currently still receive disproportionate social, political and economic benefits in these global south partnerships while simultaneously contributing to or benefiting from the ongoing exploitation of marginalized groups. There is a common trend of academic institutions engaging in collaborations with global south institutions with an overwhelming emphasis on what they will 'acquire' out of the partnership. Typically, US academic libraries will offer monetary or in-kind resources to a global south institution in exchange for unique informational and cultural heritage assets, such as digitized archival materials and/or unfettered access to a partner institution's collections or connections. This expectation is often accompanied by a charity discourse about how the US academic library is 'helping' the less economically advantaged partner institution in the global south. However, these so-called partnerships often result in paternalistic relationships reminiscent of colonial and neocolonial dynamics that exacerbate an already unequal power dynamic, one in which the global north organization continues to benefit disproportionately more than the organization in the global south. ${ }^{5}$ When academic

\footnotetext{
${ }^{5}$ Historically, global north archival institutions have removed cultural heritage material from the global south in order to 'preserve' it in archivally sound conditions. A common contemporary scenario is for a global north institution to digitize archival records
} 
libraries in the global north provide resources, such as grants or digitization equipment, to a global south institution, they often have an unrealistic and ahistoric expectation of receiving an economically equivalent result in return. This expectation does not recognize historic systemic and structural factors that have inhibited partner organizations from building up the infrastructure, staffing, or training that are taken for granted in the global north. A partnership based solely on resource transactions also implicitly creates a relationship of dependence that deepens power inequalities between the two organizations and does not necessarily build up the global south partner's capacity or self-sustainability. This dynamic has resulted in many cultural heritage organizations in the global south being understandably wary of working with large academic institutions in the global north because they do not want their materials to be taken or co-opted for the benefit of the large institution. Thus, it is imperative for archivists to educate ourselves and our institutions on these histories to avoid unconsciously reproducing them.

While the postcustodial theory of archives initially emerged in response to the archival challenge of managing the proliferation of electronic records, the archival profession has witnessed a resurgence of postcustodial discourse and practice in service of community-based archives, human rights archives, and indigenous archives (Caswell 2014; Kelleher 2017; O'Neal 2015; SAA 2005a). As an archivist and librarian who has worked extensively with international archival collaborations in the global south, I, too, espouse the practical and ethical imperative of implementing a postcustodial theory of archives. However, I want to reframe that model within an explicitly social justice framework by applying contributive justice in a way that can guide global south collaborations and archival functions such as appraisal, description, and access, with an aim to decolonize archival practice.

As the archivist for the Human Rights Documentation Initiative at the University of Texas at Austin, I worked with countries such as Rwanda, El Salvador, and Guatemala on postcustodial partnerships that preserved and digitized documentation of human rights violations in conflicts where the US was covertly responsible for and/or complicit in those violations (Doyle and Osorio, n.d.; Doyle and Willard 2011; Ferrogiaro 2001). Conscious of that history, our institution had an ethical and moral responsibility to consciously build a partnership that did not replicate violent inequalities within the archival collaboration. ${ }^{6}$ Despite no longer working on sensitive human rights documentation projects, I find that the same politics and unequal power dynamics remain in my current work at UCLA leading postcustodial collaborations for the preservation of and access to cultural heritage materials in Cuba. This article will draw upon experiences working with variety of countries in the global south (namely, Rwanda and Guatemala). However, the following section will focus on providing historical context for Cuba in order to clarify some of the misinformation about US and Cuba relations and to enrich our understanding of why it is necessary to decolonize archival practice through postcustodial partnerships grounded in a contributive justice ethos.

\section{Background on US-Cuba Relations}

While the full complexity of US-Cuba relations is beyond the scope of this article, I will offer a brief historical background to establish the complex political backdrop to our archival collaborations in Cuba. From the nineteenth to the mid-twentieth century, the US exercised extensive economic control in Cuba, particularly over the sugar industry. In order to maintain that economic control, the US supported political leaders who protected its economic interests, even if these leaders were repressive of the Cuban people, as was the case with the last US-backed leader, Fulgencio Batista, who was overthrown by Fidel Castro in 1959 (BBC 2018; Perez 1988). In 1960, Castro nationalized foreign-held assets, including over 166 US-owned utilities, sugar mills, petroleum, 'insurance companies, import firms, hotels, casinos, textile firms, metal plants, tobacco export firms, chemical companies, and food processing plants' (BBC 2018; Perez 1988: 326). In 1961, US President Dwight D. Eisenhower severed diplomatic relations with Cuba; in 1962, US President John F. Kennedy expanded the embargo against Cuba that remains in effect until this day, despite the opening of US-Cuba relations in 2015 (BBC 2018; US Department of State 2017). In a nutshell, the US embargo intends, with few exceptions, to restrict and criminalize the movement of people and capital between the US and Cuba. ${ }^{7}$

belonging or pertaining to global south communities and then return to the global north with digital copies of the records, perhaps leaving digital copies with the global south community but not the infrastructure to support preservation or access or the capacity to manage the digital files. For a case study that exemplifies these dynamics, see Michelle Caswell's (2011) '“Thank You Very Much, Now Give Them Back": Cultural Property and the Fight Over the Iraqi Baath Party Records.'

${ }^{6}$ For more detailed discussions of how the Human Rights Documentation Initiative implemented postcustodial partnerships, see Kelleher (2017) and Sangwand (2014a).

7 Some exceptions include US citizens being able to travel to Cuba under one of the twelve general Cuba travel licenses issued by the US Office of Foreign Assets Control; for more information on restrictions and exceptions, see ‘Cuba Sanctions' (US Department of Treasury, n.d.). 
After Fidel Castro came to power, the US attempted to assassinate him numerous times, although Executive Orders 11905 and 12036 ban the US from engaging in political assassinations; some of these attempts are well documented in CIA files (CIA 2007; CIA 2016; Prados and Jimenez-Bacardi 2016). Despite this fact, the US states that one of its reason for the embargo is Cuba's poor human rights record under Castro, even though the US embargo itself has also been called a violation of human rights in that it limits Cubans' access to food, medical care, and social services (UN 2017a; US Department of the Treasury 1992). ${ }^{8}$ If one considers the nationalization of US-owned businesses in Cuba that led up to the embargo policies, it seems evident that the US imposed the embargo as a retaliatory action, and it remains in place because of Cuba's defiance of US political and economic demands. Since 1992, the United Nations General Assembly has voted in favor of adopting a resolution to end the embargo (UN 2017b). As of the 2017 vote, out of the 193 voting countries, only the US and Israel have voted against ending the embargo (UN 2017a). As US President Barack Obama acknowledged in 2016, the embargo is an 'outdated burden on the Cuban people,' and its impacts are most acutely felt by the majority of Cubans for whom it is difficult or prohibitively expensive to procure basic goods, food items, medication, and technology (Obama 2016).

The embargo has archival implications as well. Standard archival supplies such as folders, boxes, and paper, which are already expensive by Latin American standards, are prohibitively expensive for Cuban cultural heritage institutions to obtain because they cannot be purchased or shipped from the US. Electronic equipment for digitization and digital preservation is, similarly, prohibitively expensive. Much of the software for libraries and archives is built for a technical infrastructure and internet connectivity that the country currently does not support. In spite of and as a result of these historical conditions, Cubans are enormously creative, and their ingenuity in fashioning solutions with extremely limited resources is inspiring (Marder 2015a, b). ${ }^{9}$ Yet it remains that the US embargo against Cuba and the political relationship between the two countries has profound implications for the literal preservation of the archival record in Cuba.

\section{Contributive Justice and the Global South}

As the preceding section on US-Cuba relations has hopefully demonstrated, a social justice framework is necessary in international collaborations to begin to address the systemic inequities and histories of colonial/neocolonial relations that provide the backdrop for these collaborations between the global north and south. Cognizant of these histories of colonialism and neocolonialism, I have strived to lead postcustodial partnerships for the HRDI and IDEP in ways that would not replicate these dynamics and instead center the needs of the global south institution alongside and not subordinate to those of the global north institutions. In the case of HRDI and IDEP, these collaborations have entailed conducting site visits for collection assessments and providing preservation supplies, digitization equipment, training, and, at times, funds to compensate staff for digitization and metadata work. Most importantly, however, these partnerships have aimed at building and strengthening archival capacity within the global south institution to decrease their reliance on outside institutions in the future. The following sections will provide concrete examples of efforts to decolonize postcustodial practices based on the experiences of the HRDI and IDEP. These examples will be examined through the lens of contributive justice and will extend the applicability of Caswell's (2017) suggestions for dismantling white supremacy in US archives to a transnational decolonial and postcustodial context. The guiding questions of contributive justice are the following: Does everyone have the responsibility to contribute labor and participate in social decisions? Does everyone have equal opportunities to contribute labor and participate in social decisions? With knowledge of US intervention in the global south, what should contributive justice look like, in concrete terms, in global south contexts? Clearly, the distribution of monetary and in-kind resources is needed, but global south institutions should not be viewed as passive recipients of charity; it is imperative to recognize

\footnotetext{
${ }^{8}$ The Cuban Democracy Act (CDA) states that 'Fidel Castro has demonstrated consistent disregard for internationally accepted standards of human rights and for democratic values'; CDA was enacted by Congress in 1992 'to seek a peaceful transition to democracy and a resumption of economic growth in Cuba through the careful application of sanctions directed at the Castro government and support for the Cuban people' (US Department of the Treasury 1992: 1, 2). While I am not implying that human rights violations have never occurred in Cuba under Castro, this article focuses on the impact of the US embargo on Cuban people and archives in Cuba.

9 Due to the US embargo and especially during Cuba's severe economic crisis during the Special Period in the 1990s when resources were particularly scarce, Cubans have crafted creative solutions for survival. For example, see Jenny Marder's (2015) 'How Communism Turned Cuba into an Island of Hackers and DIY Engineers.' One notable example that I have seen firsthand is from our partner organization, the Instituto de Historia de Cuba (Institute of Cuban History), which created an adjustable copy stand for digital imaging using the parts of a microfilm reader.
} 
that global south institutions possess deep expertise to contribute and that any collaborative project would fail without them at the forefront.

\section{Questioning Global North Assumptions}

'Decenter whiteness in archival practice.' (Caswell 2017: 231)

\section{'Encourage, value and give credit for language courses in MLIS programs and as continuing education.'}

(Caswell 2017: 228)

One of Caswell's first suggestions for dismantling white supremacy in archives is to decenter whiteness in archival practice. How can this suggestion translate to a decolonizing archival practice with transnational partnerships in the global south, and how can it support partners' responsibility and opportunity to contribute labor and participate in social decisions?

One concrete way is by questioning English as the lingua franca of transnational partnerships. It is unrealistic and colonialist to assume that English will be the lingua franca, yet it is common for US academic institutions to default to English in both oral and written communication and agreements because it is timeconsuming and resource intensive to find language speakers and translators. However, building a relationship with partners in the global south requires mutual respect and trust based on transparent communication, and this relationship is the basis for any successful collaboration. No clear means of communication is not only alienating to potential collaborators, but also damaging to the work itself. If partners are not able to effectively communicate, how will they work together in a meaningful way, and how will they be able to contribute to the best of their abilities? Who will want to sign a memorandum of understanding if they do not fully understand it? Before embarking on international partnerships, academic libraries must question if they have the right technical as well as linguistic expertise and cultural competencies to engage in partnerships. If they do not, they should hire archivists that not only have preservation expertise but also the linguistic and subject expertise and cultural competencies for the partner institution's country or region.

In the cases of UT Austin's partnerships in Latin America and UCLA Library's collaborations in Cuba, the archivists/project managers possess relevant graduate degrees (in this case, Latin American Studies and International Peace Studies) in addition to the MLIS/MSIS and a high level of Spanish proficiency, which enable them to build relationships with partners in the region. The archivist/project manager works closely with the relevant area studies librarian (who also possesses a graduate degree in their specialization as well language proficiency in at least one of the region's languages) to help determine content focus in conjunction with the partner organization. Notably, when there are subject-specialist librarians but no archivist/project manager with relevant subject expertise and language skills, projects in those regions tend to be less developed because there is no one able to effectively shepherd them to fruition. We have found that it is not a sustainable practice to rely solely on area studies librarians and catalogers as translators, interpreters, and project managers for preservation partnerships. They often have full workloads and professional expertise that is not necessarily based in digital archives, preservation, metadata, or digitization. It is also the responsibility of iSchools to prioritize additional language proficiencies and cultural competencies as an essential part of information professional training and for employers to actively seek and prioritize these competencies in job postings and job descriptions if they wish to pursue international partnerships.

Additionally, when engaging in these transnational collaborations, it is crucial not only to ensure that the staff involved have technical and linguistic expertise and cultural competencies, but also that the institution invests resources in the professional translation of project agreements and technical documentation. Similarly, it is also necessary to invest in interpretation if conducting training sessions or symposiums with partners. Ensuring that partners can communicate with each other will facilitate both partners having equal opportunities to contribute labor and to participate in decision-making processes.

\section{Contributive Justice and Appraisal}

'Institute participatory appraisal models that share appraisal decision-making power with people of color.... Compensate them for their labor.' (Caswell 2017: 229)

Appraisal is defined as 'the process of identifying materials offered to an archives that have sufficient value to be accessioned' (SAA 2005b). Within a decolonial archival practice, global south partners should have both the responsibility and opportunity to participate in appraisal decisions. Indeed, global south partners often have expertise informed by lived experience in addition to formal education and are most attuned to the social and political implications of their appraisal decisions in local communities. Historically, archivists 
have practiced appraisal as a unidirectional decision made by the archivist, the recognized expert on value of the historical record. However, in collaborative global north/south relationships based on a contributive justice ethos, all entities are recognized for their expertise, and partners drive appraisal decisions.

In the case of collaborations with Cuba, El Salvador, Guatemala, Nicaragua and Rwanda, partner organizations decided which collections to prioritize for digitization based on their knowledge of historical value as well as which materials are most often requested and less likely to exist elsewhere. The only parameters given by the US academic institutions were based on technical feasibility. Subject-specialist librarians provided feedback on selected options based on their knowledge of their institution's faculty and graduate students' research interests as well as general research trends, but ultimately partners chose which collections to work with. Appraisal driven by global south partners is necessary not only because they know their collections and communities' needs best, but also because they have the agency to shape their historical narratives in a way that resonates and represents them.

'Expand ... cultural values to value materials created by communities of color.... Educate yourself about what specific communities of color value.'(Caswell 2017: 229)

By applying contributive justice principles within the context of a global south collaboration, we can expand Caswell's suggestion by urging US archivists to work with their partners to preserve documentation that is not typically considered under archival purview. As archival studies scholars Anne Gilliland et al. (2008) note:

Little or no space exists within the traditional paradigm for cultures with nontextual mechanisms for recording decisions, actions, relationships, or memory, such as those embodied in oral, aural, or kinetic traditions ... archival practice has come to a realization that the cultures and beliefs of many communities today are predicated upon alternate, dual, or mixed ways of making and keeping records that to a greater or lesser extent fall outside the traditional archival paradigm. (90)

Western archival theory defines archival records by their physicality and textuality (SAA 2005c), yet, as Gilliland et al. (2008) point out, there are many forms of memory making that fall outside this narrow criteria, and archives' failure to recognize these forms impoverishes the historical record. How are archivists addressing these gaps in the historical record, particularly in global south contexts?

In 'Revolutionizing the Archival Record through Rap,' which examines Cuban hip hop as an archival record, I challenge archivists to rethink our notion of what constitutes an archival record and argue that Cuban hip hop is a potent example of an intangible archival record that provides important insight into daily life in Cuba (Sangwand 2014b). After the Cuban Revolution, the government discouraged discourse on racial difference and saw it as undermining national unity; the government instead espoused a unifying discourse of 'We are all Cuban.' Considering the aforementioned numerous attempts by the US to overthrow the Cuban government, it is understandable why the Cuban government prioritized cultivating a strong sense of national unity in the face of outside intervention. However, due to this narrative, it is difficult to find official documentation that explicitly documents the experiences of Afrocubans. The fall of the Soviet Union in the 1990s ushered in Cuba's economic crisis, called the 'Special Period in Times of Peace,' and this public discourse began to shift.

Again, it is important to recall the role of the US embargo against Cuba. When Cuba lost its main trading partner, the Soviet Union, the Cuban people acutely felt the effects of the embargo as they were no longer able to obtain basic food items, clothes, and other goods. Afrocubans were more likely to experience hardship because they were less likely to have wealthier family members who left Cuba and could send remittances from abroad. Youths who came of age in this period and did not have a period of relative abundance to compare it to were particularly discontent with the revolutionary government not living up to its promises. Similar to the role of early hip hop in the Bronx, New York, hip hop in Cuba became a way for youths, particularly Afrocuban youths, to channel and voice their discontents. Thus, hip hop is one of the few ways one can learn about contemporary, explicitly Afrocuban experiences.

While there has been extensive scholarship outside Cuba on Cuban hip hop, the scholarship relies mostly on primary sources generated or encountered during an individual's research; there are no archival repositories within or outside of Cuba that explicitly collect Cuban hip hop materials..$^{10}$ There are no easy

\footnotetext{
${ }^{10}$ While there are a handful of US archival institutions that hold collections related to hip hop (i.e., the Hip-Hop Archive Project Collection at the Schomburg Center for Research in Black Culture, the Tupac Amaru Shakur Collection at the Atlanta University Center Robert W. Woodruff Library, and the Hip Hop Collections at the Archives of African American Music and Culture at Indiana
} 
or immediate answers for how Cuban hip hop can be preserved as part of the historical record, but the archival process should account for the tangible and intangible manifestations of hip hop and be led by members of the Cuban hip hop community. ${ }^{11}$ UCLA's IDEP is experimenting with archiving Cuban hip hop by partnering with hip hop practitioners and historians in Cuba who are leading efforts to preserve hip hop history documented in the Cuban press. In addition to piloting the preservation of extant tangible Cuban hip hop documentation, IDEP has also experimented with creating documentation by hosting an artist residency with Cuban hip hop group Obsesion. Obsesion met with students and professors in numerous classes and at two public events as well as with community activist and Black Lives Matter co-founder Patrisse Cullors; Obsesion was also invited to create and record a new track with UCLA professor Bryonn Bain and LA hip hop artist Maya Jupiter. The IDEP documented the residency, and that documentation will be part of the nascent Cuban hip hop archive. The transnational relationships built during this residency both within and beyond the archives open up the possibility for a more transformative role for archives as a collaborator and facilitator of documentation in many forms. While it is too early to discuss definitive outcomes of these archival initiatives, it is an important step for archives to collaborate with partners who drive appraisal decisions and challenge archives to reconsider what is deemed 'archival.' It is unlikely that US archival institutions, as they are currently configured, will overcome these gaps in the historical record unless they collaborate with communities for whom these non-textual and intangible forms of documentation are important.

\section{Contributive Justice and Description}

"Engage communities to ask how they wish to describe themselves. Compensate them for their labor." (Caswell 2017: 228)

Caswell's above suggestion embodies a contributive justice ethos and is directly applicable to transnational global north/south collaborations. Traditionally, description is archival labor performed solely by archivists and executed in accordance with defined standards. Yet within international archival collaborations this is labor that both entities can and should have the responsibility and opportunity to contribute. While the need for standardization to facilitate discoverability and searching is important, US-based archives should account for additional modes of description that resonate with their global south partners; these archives should also solicit their partners' active involvement in developing the description process as well as the description itself. When discussing the challenges of archival description in a human rights context, archival studies scholars Stacy Wood et al. offer some guiding questions that are also useful in global north/south collaborations and speak to the importance of a contributive justice approach: 'How can archivists describe records in ways that not only reflect the contexts of the record's creation but that open up spaces for those mentioned in or related to the records to contribute their voice? How can archival description allow and make room for the multiplicity of voices in archives to speak? How can institutions foster trust by rethinking their protocols, policies and practices with respect to description?' (Wood et al. 2014: 401).

The first step of metadata creation is asking global south partners what information they want to capture or have already captured about their materials. This information can help determine how to best map the information to existing metadata templates or how to find new methods to incorporate the information in ways that are meaningful for both the global south partner and US academic institution. In the cases of UT Austin's HRDI and UCLA's IDEP collaborations, all partner institutions are responsible for the descriptive metadata for their collections. On a practical level, it is often necessary for partner organizations to describe their own material because the task often requires subject expertise and language skill sets not easily found within the US archival institution. More importantly, however, local description and organization practices enable global south partners to acquire new skills by building archival and preservation capacity into their organization as well as promoting their community's ownership of its cultural patrimony. As with appraisal, this contributive justice approach to description enables partners to exercise agency on the historical record.

University), the most prominent archives dedicated to hip hop are Harvard's Hiphop Archive \& Research Institute (http:// hiphoparchive.org/), the Cornell Hip Hop Collection (http://rmc.library.cornell.edu/hiphop/), and the University of Houston's Houston Hip Hop Research Collection (https://libraries.uh.edu/branches/special-collections/houston-hip-hop/). However, the aforementioned institutions focus exclusively on US hip hop; while Harvard's Hiphop Archive \& Research Institute (n.d.) states that 'the Archive is a record of all specific-to-Hiphop activity, ranging from local to international,' the international aspect is not represented on their site, as all the highlighted artists and albums are US based.

${ }^{11}$ For more information on how US institutions are archiving hip hop, see Morgan (2004), Leach (2008), Moyer (2013), Jacinto (2013). 
In the case of UT Austin's collaboration with the Kigali Genocide Memorial (KGM) in Rwanda, the KGM staff who indexed the Kinyarwanda-language video testimonies from genocide survivors came to the work with deep knowledge as both native Kinyarwanda speakers and genocide survivors themselves. While KGM was careful to limit indexers' time with the videos in order to mitigate re-traumatization, one might also speculate that there may be a therapeutic outcome for indexers, as members of the impacted community, in processing trauma collectively and participating in the preservation of survivor narratives around the genocide.

Compensating people in the global south for their labor is a challenge, particularly for public US institutions, but there may be creative solutions available. While one cannot place a monetary value on cultural heritage and human rights documentation, US archives are equipped to purchase collections and may opt to purchase digital copies of a global south partner's collection at the rate of labor costs that would be required to digitize them. While it may be more affordable for the US institution to digitize the collection itself, embracing a contributive justice ethos that enables the global south partner to contribute labor and build up their own archival capacity and expertise is a more ethical process. It is imperative that US institutions address the compensation question internally within the organization and determine if this is achievable before embarking on partnerships in the global south. The answer to this question may limit which global south organizations are able and willing to partner with a US institution. A prominent cultural organization in Cuba stated that they would not be able to partner with a US institution unless their labor could be compensated because they have limited staff and other competing priorities. If US archives are not able or willing to compensate global south partners for their labor, it may mean that US institutions will only partner with better resourced organizations, which impacts which parts of the historical record will be preserved and may result in reinforcing dominant historical narratives.

\section{Contributive Justice and Access}

"Train staff at all levels to identify and disrupt white supremacist assumptions." (Caswell 2017: 230)

Caswell's suggestions for dismantling white supremacy in archives' access policies focus primarily on the physical spaces. However, access within the context of transnational global north/south partnerships is often mediated in the digital realm. Within the US archival context, open online access is often a requirement for digitization grant funding. While this is an understandable, and indeed a necessary, goal for government records and scholarship locked behind exorbitantly expensive paywalls, online public access is not always an ethical or even relevant goal for global south partners. If US archives adopt contributive justice principles for access, access policies should be driven by global south partner organizations who are experts in how their primary communities will want to access their materials. After working with partners across seven countries, I learned that there is no 'one size fits all' approach because access policies differed across partnerships and even across the different collections of the same partner. While partners were generally in favor of providing broad access to their materials for educational purposes, there were some materials held at the Human Rights Documentation Initiative for which broad access would compromise the safety and privacy of the people documented within. For example, broad access might betray the location of internally displaced people in Burma, or open up a genocide survivor in Rwanda to retaliation, or disclose private information such as sexual assault or HIV/AIDS status. In the case of the Guatemala National Police Archive, online public access to their collection served as a statement against impunity and state secrecy. In order to address privacy concerns, the HRDI explored offering tiered levels of access-materials available online, but anonymized or excerpted; or available on-site, but not online; or not available for a certain number of years. While protecting privacy is not a new practice within archives, US archives must continue to educate their institutions and funders about the necessity of nuanced understandings and implementations of access. ${ }^{12}$

In the case of Cuba, online public access is not so much an ethical question as it is a mostly irrelevant one. As with most archives, partners in Cuba generally support broad access to their materials; however, this goal does not serve the access needs of their institution or their constituents in Cuba because internet access is extremely limited on the island. Currently, the majority of Cubans connect to the internet through public Wi-Fi parks. If you purchase an internet card through the official communications bureau, it costs about $\$ 2$ an hour. As of 2015, the average Cuban salary is $\$ 28$ a month, and with internet access costing over a quarter of a weekly salary, it is unsurprising why online public access to archival collections is a mostly irrelevant

\footnotetext{
${ }^{12}$ For a nuanced discussion of access, see WITNESS (2013: 75-85) and Kim Christen (2012).
} 
goal (ONEI 2016). ${ }^{13}$ Even people who work for the government, and are more likely to have internet access at work, often have slower connections and are unable to access websites designed for people with faster connections. Online public access for Cuban cultural heritage institutions looks vastly different from that of their US counterparts.

In the case of limited access in Cuba, UCLA IDEP is experimenting with short- to medium-term solutions for Cinemateca de Cuba, the national film archives of Cuba. IDEP digitized Cinemateca's collection of film posters, but, unlike our other partners in Cuba, Cinemateca was not interested in obtaining digitization equipment, due to limited technical expertise and relatively small print collections. Instead, Cinemateca requested a way to manage the digital poster collection and provide access to their patrons. Since they would not be able to connect to the UCLA website for public access, we installed a local instance of Omeka and Collective Access on a laptop so that Cinemateca staff and users could access and maintain their collections without connecting to the internet. Additionally, UCLA installed a local Wi-Fi hotspot that enables multiple users to access the collection, thus extending the usability of the laptop beyond one user. While this does not address broader access within the country, it is a short- to medium-term solution that meets the immediate access needs of our partner institution. This is an important example of where a contributive justice model provides more benefit than a distributive justice model. If UCLA focused solely on what it would get out of providing local access to Cinemateca's digital collection, it would be difficult to justify because the solution did not directly benefit UCLA. However, by focusing on how UCLA could contribute to providing equitable access to Cinemateca's collections, UCLA was not only able to work with Cinemateca to meet their goals, but it also pushed UCLA to think creatively, resulting in a solution that has the potential to be useful for contexts outside of Cuba as well.

Similar to Cuba, Rwanda did not have consistent or widespread internet access when the HRDI began collaborating with the Kigali Genocide Memorial (KGM) in 2008, nor the capacity or infrastructure to offer their audiovisual materials online. These circumstances required HRDI and KGM to think creatively and practically about digital access in global north and south contexts. In order to facilitate on-site access to KGM's valuable materials of genocide survivor testimonies, the HRDI helped KGM install a content management system locally for users to consult on-site at the museum's documentation center in Kigali. HRDI staff would then copy the publicly open contents of the site onto an instance hosted by UT Austin for worldwide access. Despite the website being hosted at UT Austin, KGM selected a .rw domain name in order to highlight KGM, and not UT Austin, as the physical and intellectual holders of their archival material. ${ }^{14}$ This was the ideal scenario for KGM, but other partners requested different approaches to access. In the case of the Guatemala National Police Archive (one of the largest human rights archives in the world, with over 10 million documents), they requested that UT Austin be publicly visible as the host of their digital archive because the international partnership provided a certain level of legitimacy and protection from their political opponents who may be motivated to close the archive. ${ }^{15}$ As these examples from Cuba, Rwanda, and Guatemala demonstrate, there is no singular approach to access. Access is driven by an archive's historical and political factors and should be determined by the communities to whom the material belongs; global north institutions should not impose a standard of online open access as a requirement for the partnership.

\section{Conclusion}

As this article has hopefully demonstrated, the colonial and neocolonial histories between the global north and south necessitate a justice-based framework for postcustodial partnerships and require that 'the success of partnerships ... between Western repositories and ... organizations from the global south, must be evaluated on an ongoing basis" (Caswell 2014b: 319). The contributive justice framework that calls for the agency and responsibility of all actors to achieve justice is particularly useful for undoing some of the colonial patterns that have separated global south communities from their histories. US archives must continually ask their partners and themselves: Does everyone have the responsibility to contribute labor and participate in social decisions? Does everyone have the equal opportunity to contribute labor and participate in social decisions?

Caswell (2017) states that her list of proposed concrete actions to dismantle white supremacy in archives 'call for nuance, context, and an awareness that oppression is structural' (227). Likewise, I present the examples from postcustodial partnerships in the global south not as perfect solutions, but rather as a starting point for discussing and reimagining how we can decolonize archival assumptions and practices

\footnotetext{
13 This was the most recent salary statistic available online through Cuba's National Office of Statistics.

14 The Genocide Archive of Rwanda can be accessed at http://www.genocidearchiverwanda.org.rw.

15 The digital archive of the Guatemala National Police Archive can be accessed at https://ahpn.lib.utexas.edu.
} 
in the realms of relationship building, appraisal, description and access. Global north/south partnerships should be responsive to their changing social and political contexts and recognize how these contexts might impact abilities to participate. Partnerships, like preservation, are an iterative and an imaginative process. More broadly, in archivists' role as memory workers, we must continue to reinterpret the past and reimagine our archival frameworks to help undo the archival silences and violences within our historical narratives. As Heather Heyer's death in Charlottesville showed the world, the stakes are high in shaping our collective histories, and we all have the responsibility of envisioning and enacting liberatory archival futures.

\section{Acknowledgements}

Thank you to Todd Honma for his presentation 'Positionality, Epistemology, and New Paradigms in LIS: A Critical Dialog with Clara Chu' at the Pushing the Margins: Women of Color in LIS Symposium held at UCLA in July 2017, which sparked the inspiration for applying concepts of contributive justice to postcustodial archival practice; additional thanks to Honma for sharing some of his unpublished work on contributive justice in LIS with me after the symposium (which has since been published in Pushing the Margins: Women of Color and Intersectionality in LIS, Library Juice Press, 2018). I am also grateful to Gabe Solis for providing invaluable advice on an earlier draft of this article as well as to the editors and peer reviewers for their excellent feedback. Any errors and shortcomings in this work are my own.

\section{Competing Interests}

The author has no competing interests to declare.

\section{References}

Barker, Nicolas. 2007. "Introduction." In: Celebrating Research: Rare and Special Collections from the Membership of the Association of Research Libraries, Philip N. Cronenwett, Kevin Osborn, and Samuel A. Streidts (eds.). Accessed March 15, 2018. http://www.celebratingresearch.org/intro/intro.html. Archived at: https://perma.cc/5EME-KTA2.

BBC. 2018. "Cuba profile - Timeline." Accessed March 15, 2018. http://www.bbc.com/news/world-latinamerica-19576144. Archived at: https://perma.cc/HT4Q-RA44.

Britz, Johannes J. 2004. "To Know or Not to Know: A Moral Reflection on Information Poverty." Journal of Information Science, 30(3): 192-204. DOI: https://doi.org/10.1177/0165551504044666

Britz, Johannes J., and Peter J. Lor. 2003. "A Moral Reflection on the Information Flow from the South to North: An African Perspective." Libri, 53(3): 160-73. Accessed September 26, 2018. DOI: https://doi. org/10.1515/LIBR.2003.160

Britz, Johannes J., and Peter J. Lor. 2004a. "A Moral Reflection on the Digitization of Africa's Documentary Heritage." IFLA Journal, 30(3): 216-23. Accessed September 26, 2018. DOI: https://doi. org/10.1177/034003520403000304

Britz, Johannes J., and Tomas A. Lipinski. 2001. "Indigenous Knowledge: A Moral Reflection on Current Legal Concepts of Intellectual Property." Libri, 51(4): 234-46. Accessed September 26, 2018. DOI: https://doi. org/10.1515/LIBR.2001.234

Caswell, Michelle. 2011. “'Thank You Very Much, Now Give Them Back': Cultural Property and the Fight Over the Iraqi Baath Party Records." The American Archivist, 74(1): 211-40. Accessed March 15, 2018. DOI: https://doi.org/10.17723/aarc.74.1.4185u8574mu84041

Caswell, Michelle. 2014a. "Inventing New Archival Imaginaries: Theoretical Foundations for Identity Based Community Archives." In: Identity Palimpsests: Archiving Ethnicity in the U.S. and Canada, Dominique Daniel, and Amalia Levi (eds.), 35-53. Sacramento, CA: Litwin Books.

Caswell, Michelle. 2014b. "Toward a Survivor-Centered Approach to Records Documenting Human Rights Abuse: Lessons from Community Archives." Archival Science, 14(3-4): 307-22. Accessed March 15, 2018. DOI: https://doi.org/10.1007/s10502-014-9220-6

Caswell, Michelle. 2015. Archiving the Unspeakable: Silence, Memory, and the Photographic Record. Madison, WI: University of Wisconsin Press.

Caswell, Michelle. 2017. "Teaching to Dismantle White Supremacy in Archives." Library Quarterly:Information, Community, Policy, 87(3): 222-35. DOI: https://doi.org/10.1086/692299

Caswell, Michelle, Ricky Punzalan, and T-Kay Sangwand. 2017. "Critical Archival Studies: An Introduction." Journal of Critical Library and Information Studies, 1(2): 1-8. Accessed March 15, 2018. DOI: https://doi. org/10.24242/jclis.v1i2.50 
Central Intelligence Agency (CIA). 2007. The CIA's Family Jewels. Washington, DC: National Security Archive. Accessed March 15, 2018. https://nsarchive2.gwu.edu/NSAEBB/NSAEBB222/.

Central Intelligence Agency (CIA). 2016. Official History of the Bay of Pigs Operation, 1-5. Washington, DC: Central Intelligence Agency. Accessed March 15, 2018. https://www.cia.gov/library/readingroom/ collection/bay-pigs-release.

Christen, Kim. 2012. "Does Information Really Want to Be Free? Indigenous Knowledge Systems and the Question of Openness." International Journal of Communications, 6: 2870-93. Accessed March 15, 2018. http://ijoc.org/index.php/ijoc/article/view/1618/828.

Doyle, Kate, and Carlos Osorio. n.d. "US Policy in Guatemala, 1966-1996." Accessed March 15, 2018. https:// nsarchive2.gwu.edu/NSAEBB/NSAEBB11/docs/.

Doyle, Kate, and Emily Willard. 2011. "Learn from History, 31 $1^{\text {st }}$ Anniversary of the Assassination of Archbishop Oscar Romero." Accessed March 15, 2018. https://nsarchive2.gwu.edu/NSAEBB/ NSAEBB339/index.htm.

Drake, Jarrett. 2016. "Liberatory Archives: Towards Belonging and Believing." Accessed March 15, 2018. https://medium.com/on-archivy/liberatory-archives-towards-belonging-and-believing-part-1d26aaeb0edd1. Archived at: https://perma.cc/3DSK-YE9D.

Eriksen, Thomas Hylland. 2015. "What's Wrong with the Global North and the Global South?" In: Concepts of the Global South - Voices from Around the World, Andrea Hollington, Oliver Tappe, Tijo Salverda, and Tobias Schwarz (eds.), 3-4. Cologne, Germany: Global South Studies Center. Accessed March 15, 2018. http://kups.ub.uni-koeln.de/6399/.

Ferrogiaro, William. 2001. "The US and the Genocide in Rwanda 1994: Evidence of Inaction." Accessed March 15, 2018. https://nsarchive2.gwu.edu//NSAEBB/NSAEBB53/index.html.

Gilliland, Anne. 2011. "Neutrality, Social Justice, and the Obligations of Archival Education and Educators in the Twenty-First Century." Archival Science, 11(3-4): 193-209. Accessed September 26, 2018. DOI: https://doi.org/10.1007/s10502-011-9147-0

Gilliland, Anne, Sue McKemmish, Kelvin White, Yang Lu, and Andrew Lau. 2008. "Pluralizing the Archival Paradigm: Can Archival Education in Pacific Rim Communities Address the Challenge?" The American Archivist, 71(1): 87-117. Accessed March 15, 2018. DOI: https://doi.org/10.17723/ aarc.71.1.781w61g4r2kh3708

Gomberg, Paul. 2007. How to Make Opportunity Equal: Race and Contributive Justice. Malden, MA: Blackwell Publishing. DOI: https://doi.org/10.1002/9780470692431

Gomberg, Paul. 2016. "Why Distributive Justice Is Impossible but Contributive Justice Would Work." Science \& Society, 80(1): 31-55. Accessed September 22, 2018. DOI: https://doi.org/10.1521/siso.2016.80.1.31

Harris, Verne. 2007. Archives and Justice. Chicago, IL: Society of American Archivists.

Hiphop Archive \& Research Institute. n.d. "Mission." Accessed September 25, 2018. http://hiphoparchive. org/about/mission. Archived at: https://perma.cc/S7JG-FL8C.

Jacinto, Irlanda Esteli. 2013. "Cultural Competence in the Archive: A Case Study of the University of Houston Hip Hop Collection." MA thesis, University of Arizona.

Kelleher, Christian. 2017. "Archives Without Archives: (Re)locating and (Re)defining the Archive Through Post-Custodial Praxis." Journal of Critical Library and Information Studies, 1(2): 1-30. Accessed March 15, 2018. DOI: https://doi.org/10.24242/jclis.v1i2.29

Leach, Andrew. 2008. "'One Day It'll All Make Sense: Hip-Hop and Rap Resources for Music Librarians." Quarterly Journal of the Music Library Association, 65(1): 9-37. Accessed September 26, 2018. https:// www.jstor.org/stable/30163606.

Lipinski, Tomas A., and Johannes Britz. 2000. "Rethinking the Ownership of Information in the $21^{\text {st }}$ Century: Ethical Implications." Ethics and Information Technology, 2(1): 49-71. Accessed September 26, 2018. DOI: https://doi.org/10.1023/A:1010064313976

Lor, Peter Johan, and Johannes Britz. 2004b. "Digitization of Africa's Documentary Heritage: Aid or Exploitation?" Journal of Information Ethics, 13(2): 78-93.

Lor, Peter Johan, and Johannes Jacobus Britz. 2007. "Is a Knowledge Society Possible without Freedom of Access to Information." Journal of Information Science, 33(4): 387-97. Accessed September 26, 2018. DOI: https://doi.org/10.1177/0165551506075327

Marder, Jenny. 2015a. "How Communism Turned Cuba Into an Island of Hackers and DIY Engineers." Accessed March 15, 2018. https://www.pbs.org/newshour/science/isolation-generation-master-inventors-cuba. Archived at: https://perma.cc/2BTS-39Y5. 
Marder, Jenny. 2015b. "Photo essay: The Bizarre, Brilliant and Useful Inventions of Cuban DIY Engineers." Accessed March 15, 2018. https://www.pbs.org/newshour/science/bizarre-brilliant-useful-inventionscuban-diy-engineers. Archived at: https://perma.cc/DLU3-TRP8.

Mehra, Bharat, Kevin S. Rioux, and Kendra S. Albright. 2010. "Social Justice in Library and Information Science." In Encyclopedia of Library and Information Sciences, 3rd ed., Marcia J. Bates, and Mary Niles Maack (eds.), 4820-36. New York: Taylor \& Francis.

Merlo-Vega, José Antonio, and Clara M. Chu. 2015. "Out of Necessity Comes Unbridled Imagination for Survival: Contributive Justice in Spanish Libraries during Economic Crisis." Library Trends, 64(2): 299328. Accessed March 15, 2018. DOI: https://doi.org/10.1353/lib.2015.0051

Morgan, Marcyliena. 2004. "Preserving Hip Hop Culture." Socialism and Democracy, 18(2): 207-214. Accessed September 26, 2018. DOI: https://doi.org/10.1080/08854300408428408

Moyer, Matthew. 2013. “Cornell's Hip Hop Collection.” Library Journal, 138(16): 55.

Obama, Barack. 2016. "Obama: U.S. Embargo Is 'an Outdated Burden on the Cuban People."” Chicago Tribune. March 22, 2016. Accessed March 15, 2018. http://www.chicagotribune.com/news/86300157-132.html.

Oficina Nacional de Estadística e Información (ONEI). 2016. Anuario Estadístico de Cuba 2015: Capítulo 7: Empleo y Salarios. Havana, Cuba: ONEI. Accessed March 15, 2018. http://www.one.cu/aec2015/07\%20 Empleo\%20y\%20Salarios.pdf.

O'Neal, Jennifer. 2015. "The Right to Know: Decolonizing Native American Archives." Journal of Western Archives, 6(1): 1-17. Accessed March 15, 2018. https://digitalcommons.usu.edu/westernarchives/ vol6/iss $1 / 2$.

Perez, Louis. 1988. Cuba: Between Reform and Revolution. New York: Oxford University Press.

Prados, John, and Arturo Jimenez-Bacardi. 2016. "Gerald Ford White House Altered Rockefeller Commission Report in 1975; Removed Section on CIA Assassination Plots." Washington DC: National Security Archive. Accessed March 15, 2018. https://nsarchive.gwu.edu/briefing-book/2016-02-29/gerald-ford-whitehouse-altered-rockefeller-commission-report-1975-removed. Archived at: https://perma.cc/GLH6-2A96.

Sangwand, T-Kay. 2014a. "Human Rights Archiving: From Postcustodial Theory to Praxis." Archival Outlook, 10-11. July/August 31, 2014. Accessed March 15, 2018. http://www.bluetoad.com/publication/?i=2181 77\&pre=1\#\{“issue_id":218177,"page": 12 .

Sangwand, T-Kay. 2014b. "Revolutionizing the Archival Record Through Rap: Cuban Hip Hop and Its Implications for Reorienting the Archival Record." In: Through the Archival Looking Glass: A Reader on Diversity and Inclusion, Mary A. Caldera, and Kathryn M. Neal (eds.), 91-110. Chicago, IL: Society of American Archivists.

Sangwand, T-Kay. 2015. "Decolonizing Archival Practice and Diversifying the Historical Record through Human Rights Archiving." Keynote presentation at Digital Humanities Forum, Lawrence, Kansas, September 25. Accessed September 24, 2018. https://youtu.be/2MXUD8z1pWE.

Schwarz, Joan, and Terry Cook. 2002. "Archives, Records, and Power: The Making of Modern Memory." Archival Science, 2(1): 1-19. Accessed September 26, 2018. DOI: https://doi.org/10.1007/BF02435628

Schwarz, Tobias, and Manuela Boatca. 2015. "Not Having Neutral Terms Does Not Equal Having No Terms At All." In: Concepts of the Global South - Voices from Around the World, Andrea Hollington, Oliver Tappe, Tijo Salverda, and Tobias Schwarz (eds.), 16-18. Cologne, Germany: Global South Studies Center. Accessed March 15, 2018. http://kups.ub.uni-koeln.de/6399/.

Society of American Archivists (SAA). 2005a. "Postcustodial Theory of Archives." Accessed March 15, 2018. https://www2.archivists.org/glossary/terms/p/postcustodial-theory-of-archives.

Society of American Archivists (SAA). 2005b. "Appraisal." Accessed March 15, 2018. https://www2.archivists. org/glossary/terms/a/appraisal.

Society of American Archivists (SAA). 2005c. "Record." Accessed March 15, 2018. https://www2.archivists. org/glossary/terms/r/record.

Sutherland, Tonia. 2017. "Archival Amnesty: In Search of Black American Transitional and Restorative Justice." Journal of Critical Library and Information Studies, 1(2): 1-23. Accessed September 26, 2018. DOI: https://doi.org/10.24242/jclis.v1i2.42

United Nations (UN) General Assembly. 2017a. "As General Assembly Adopts Annual Resolution Urging End to United States Embargo on Cuba, Delegates Voice Concern About Possible Reversal of Previous Policy." Accessed March 15, 2018. https://www.un.org/press/en/2017/ga11967.doc.htm. Archived at: https:// perma.cc/M2DR-GMFY. 
United Nations (UN) General Assembly. 2017b. Necessity of Ending the Economic, Commercial and Financial Embargo Imposed By the United States of America against Cuba. A/72/L.2 (October 17). Accessed March 15, 2018. https://undocs.org/A/72/L.2.

United States Catholic Bishops. 1986. "Economic Justice for All: Pastoral Letter on Catholic Social Teaching and the US Economy." Accessed September 23, 2018. http://www.usccb.org/upload/economic_justice_ for_all.pdf.

US Department of State. 2017. "Cuba Sanctions." Accessed March 15, 2018. https://www.state.gov/e/eb/ tfs/spi/cuba/.

US Department of the Treasury. 1992. "Cuban Democracy Act (CDA)." Washington DC: US Department of the Treasury. Accessed March 15, 2018. https://www.treasury.gov/resource-center/sanctions/Documents/ cda.pdf.

US Department of the Treasury. n.d. "Cuba Sanctions." Accessed March 15, 2018. https://www.treasury.gov/ resource-center/sanctions/Programs/Pages/cuba.aspx.

WITNESS. 2013. Activists' Guide to Archiving Video. Brooklyn, NY: WITNESS. Accessed March 15, 2018. https://archiving.witness.org.

Wood, Stacy, Kathy Carbone, Marika Cifor, Anne Gilliland, and Ricky Punzalan. 2014. "Mobilizing Records: Re-framing Archival Description to Support Human Rights." Archival Science, 14: 397-419. Accessed September 26, 2018. DOI: https://doi.org/10.1007/s10502-014-9233-1

Zinn, Howard. 1977. "Secrecy, Archives, and the Public Interest." Midwestern Archivist, 2(2): 14-27. Accessed September 26, 2018. https://www.jstor.org/stable/41101382.

How to cite this article: Sangwand, T-Kay. 2018. Preservation is Political: Enacting Contributive Justice and Decolonizing Transnational Archival Collaborations. KULA: knowledge creation, dissemination, and preservation studies 2(1): 10. DOl: https://doi.org/10.5334/kula.36

Submitted: 17 March $2018 \quad$ Accepted: 03 October $2018 \quad$ Published: 29 November 2018

Copyright: (c) 2018 The Author(s). This is an open-access article distributed under the terms of the Creative Commons Attribution 4.0 International License (CC-BY 4.0), which permits unrestricted use, distribution, and reproduction in any medium, provided the original author and source are credited. See http://creativecommons.org/ licenses/by/4.0/. $\mathrm{lu}\left[\begin{array}{l}\text { KULA: Knowledge creation, dissemination, and preservation studies is a peer-reviewed } \\ \text { open access journal published by Ubiquity Press. }\end{array}\right.$ 